\title{
Crossrail project: managing geotechnical risk on London's Elizabeth line
}

Mike Black MSc, CGeol, CSci, FGS

Head of Geotechnics, Crossrail, London, UK

Understanding the ground and the specific geotechnical risks it presented was critical for successful delivery of Crossrail, the $\mathbf{f 1 4 . 8}$ billion project to deliver the Elizabeth line east-west railway across London, UK. Focusing specifically on the central tunnelled section, this paper describes the broad geological setting of the scheme and what were initially perceived to be the key geotechnical hazards. It further describes, with selected examples, how through detailed desk studies, targeted ground investigations and comprehensive client-led interpretative reporting, the specific risks posed by these hazards were more clearly defined. Appropriate mitigation was then developed both during design and delivery to eliminate or reduce these risks to manageable levels.

\section{Introduction}

Crossrail is a $£ 14 \cdot 8$ billion project to deliver the Elizabeth line - a new high-frequency, high-speed suburban railway serving London and its surrounding regions. Due for full operation by 2019, the line stretches from Berkshire, west of London, to Essex and Kent in the east - an alignment that measures over $100 \mathrm{~km}$. Of this, $42 \mathrm{~km}$ comprises the central tunnelled route between Royal Oak portal, near Paddington, and Pudding Mill Lane portal and Plumstead portal, north-east and south-east of the city, respectively (Figure 1).

Within the central tunnelled route there are eight new belowground stations, five permanent shafts, two cross-over structures, two junctions and a number of cross-passages and sumps. Additionally, there were a multitude of temporary shafts and other structures needed for logistical and programme reasons during construction.

With a programme of such size and complexity, it was clear from the outset that understanding the geology and the specific geotechnical risks was going to be critical for successful delivery.

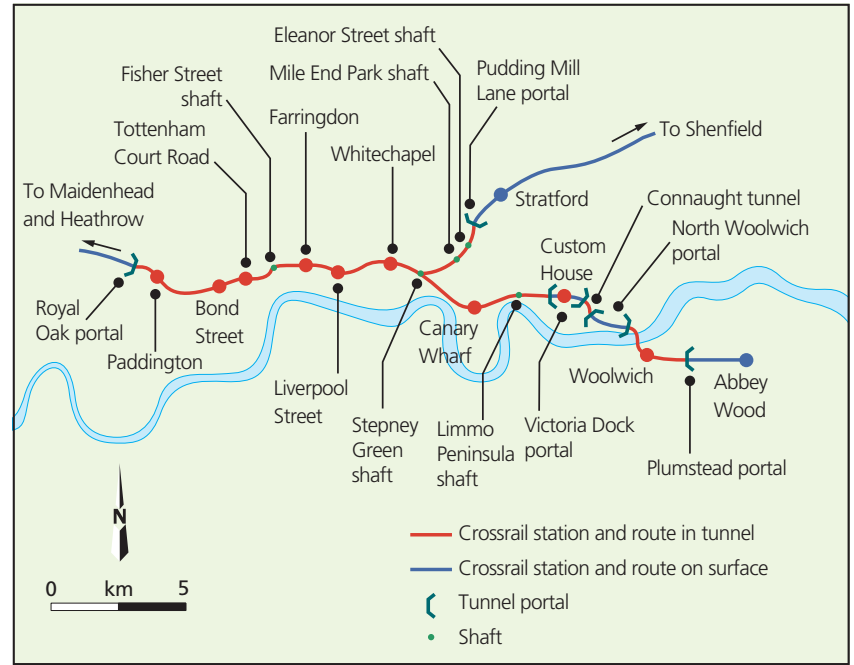

Figure 1. Plan of the central tunnelled section of the new Elizabeth line across London
Focusing specifically on the central tunnelled section, this paper aims to describe the geological setting of the scheme and what were initially perceived to be the key geotechnical risks. It will go on to describe how targeted ground investigations were designed and implemented to inform and assess the extent of these risks and how client-led interpretative reporting ensured consistency in geotechnical design across the programme.

The paper will then explain to what extent expected risks manifested during construction. It will conclude by describing what lessons have been learned during the construction of the civil works both in terms of our understanding of London geology and the way in which certain geotechnical risks are managed during construction.

\section{Geology of the central tunnelled section}

The Crossrail tunnels and underground stations are located wholly within the London basin, a large, east-west trending geological syncline that sits between the high ground of the Chilterns to the north-west of London and the North Downs to the south of the city. Table 1 shows the strata contained within the London basin that are encountered within the profile of the Crossrail project. These consist of the Cretaceous Chalk Formation, overlain by the Palaeogene succession of the Thanet Sand Formation, Lambeth Group (comprising the Upnor, Woolwich and Reading Formations) and the Harwich and London Clay Formations. Lying

Table 1. Simplified stratigraphy of the London basin

\begin{tabular}{|c|c|c|}
\hline Period & Series & Deposit \\
\hline \multirow[t]{2}{*}{ Quaternary } & Holocene & $\begin{array}{l}\text { Made ground } \\
\text { Alluvium }\end{array}$ \\
\hline & Pleistocene & $\begin{array}{l}\text { Langley Silt } \\
\text { River Terrace Deposits }\end{array}$ \\
\hline \multirow[t]{2}{*}{ Palaeogene } & Eocene & $\begin{array}{l}\text { London Clay Formation } \\
\text { Harwich Formation }\end{array}$ \\
\hline & Palaeocene & $\begin{array}{l}\text { Lambeth Group } \\
\text { Thanet Sand Formation }\end{array}$ \\
\hline Cretaceous & Upper Cretaceous & Chalk \\
\hline
\end{tabular}


on top of these are the more recent deposits of the River Terrace gravels, alluvium and made ground. The palaeoenvironments and structural setting of the UK at the time of deposition for each of these strata is further described by Davis (2016). Figure 2 shows the geological long-section for the Crossrail central area.

The western half of the Crossrail tunnelled route is largely constructed in London Clay, a stiff overconsolidated clay that has relatively small amounts of free water and is generally well-suited to tunnelling. Beneath this, although not present everywhere, is the Harwich Formation. This is typically less than $2 \mathrm{~m}$ thick and consists of a mixture of sands and clays, with occasional gravel and is frequently associated with high water flows. As the route travels eastwards, the tunnels pass down through the stratigraphic sequence into the highly variable Lambeth Group deposits. These can be particularly challenging for tunnelling and sub-surface excavation due to the variability of material types ranging from stiff clays through to loose sands and gravels, hard limestone layers and shelly beds. This variability can lead to irregularly distributed and unexpected water flows and may result in instability during excavation.

Further east still, the route passes down into the Thanet Sand Formation. These are typically fine to medium poorly graded sands and silts. This Formation and the lower units of the Lambeth Group and underlying Chalk constitute the main aquifer in London and are generally fully saturated where they are encountered by the Crossrail tunnels with the exception of specific locations where groundwater control measures have been employed. Finally, in the south-eastern section that includes the Thames tunnels, the route passes into the Chalk Formation, a weak limestone that contains flints in continuous bands or nodules and significant fracturecontrolled water flow.

Royse et al. (2012) describe the various contemporaneous and post-depositional orogenic events that resulted in the structure of the London basin that we see today. Associated with the main east-west trending folding are some significant known faults that intersect the Elizabeth line route (Figure 3). Aldiss (2013) describes the under-representation of faulting in central London in existing literature as largely due to apparent homogeneity and lack of marker bands in the London Clay. Understanding of the geological structure of certain areas has increased significantly as a result of the Crossrail works.

\section{Geotechnical hazards and risk}

With a good understanding of the geological setting, enhanced by a comprehensive set of geotechnical desk studies undertaken over a number of years since the project's first incarnation in the early 1990 s, a number of key geotechnical hazards and the consequent risks that they pose were identified early in the feasibility design process. A number of these hazards and risks were recognised from reviews of other major tunnelling projects in London,

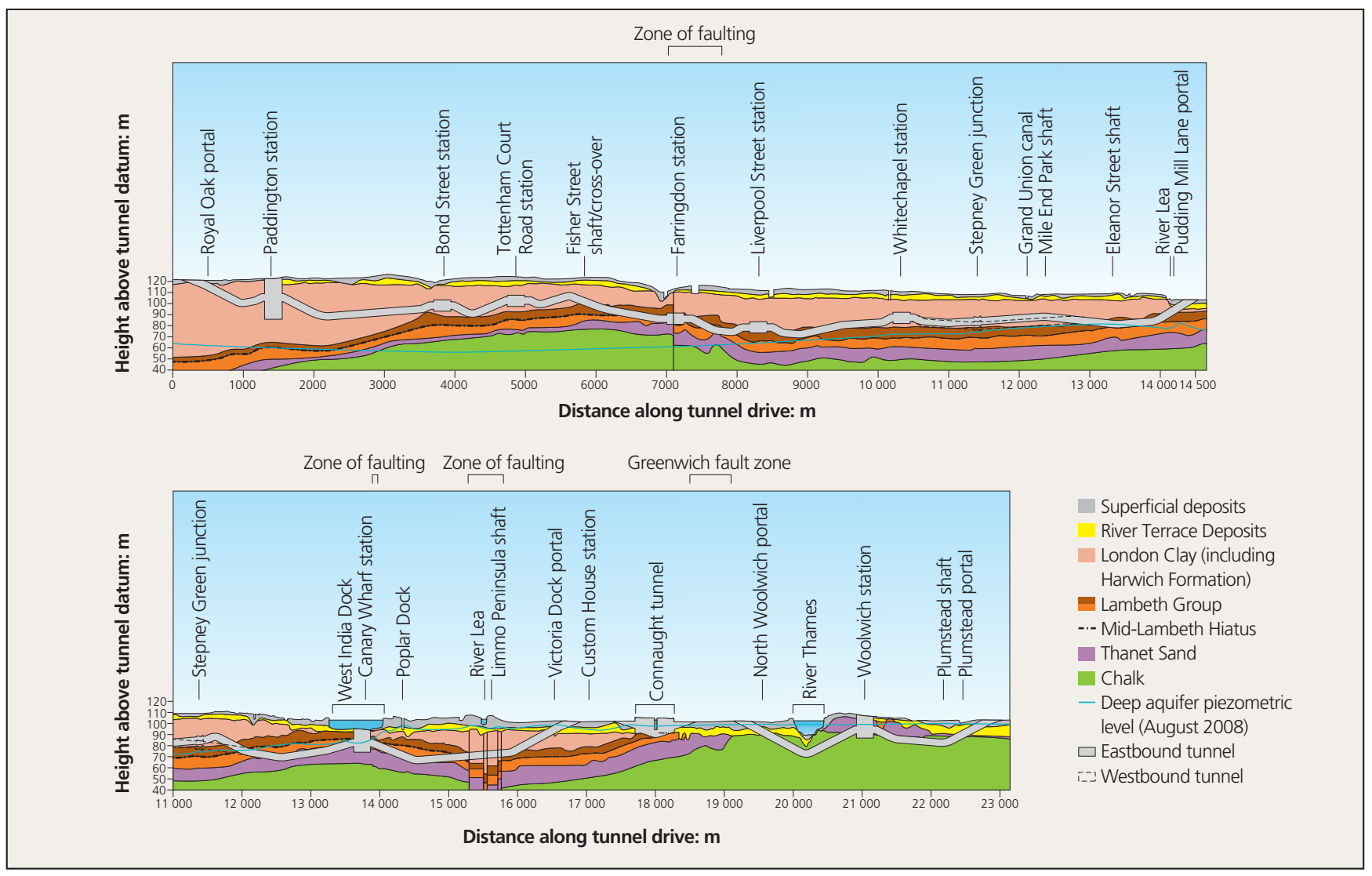

Figure 2. Geological long-sections of the central tunnelled section, which forks at Stepney Green (vertical scale exaggerated ×20) 


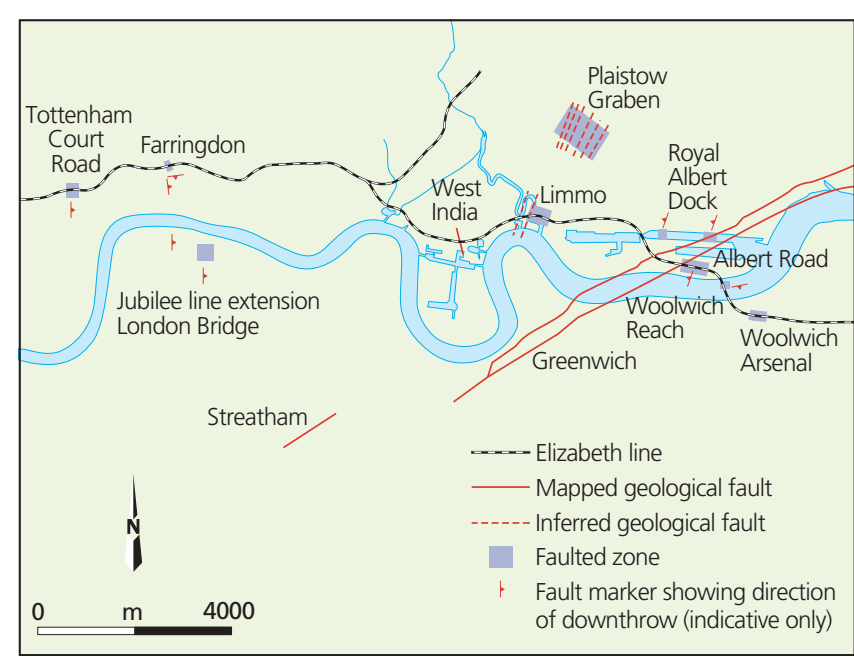

Figure 3. Significant regional faults intersect the central tunnelled section of the Elizabeth line

specifically the Jubilee line extension project and the High Speed 1 railway, which were similar in their scale and tunnelling methods employed. The risks had either manifested during construction or had been successfully avoided through design or mitigation during construction.

Key hazards included the following

- groundwater - specifically the management of groundwater during tunnelling and excavation, long-term groundwater levels and gas entrapment from dewatering recovery

- mixed face conditions - includes variable strata such as the Lambeth Group as well as faulted ground and drift-filled hollows, leading to a risk of instability of the ground and flow paths for perched groundwater

- hard strata - particularly limestone and cemented units in the Lambeth Group and claystones in the London Clay

- aggressive ground and groundwater - particularly with regard to the long-term durability of concrete and cast-iron tunnel segments

- obstructions - particularly the presence of deep piles and foundations, wells and boreholes

- abrasive ground - particularly with regard to flints in the Chalk and the dense Thanet Sand strata

- unexploded ordnance.

The significance of these hazards was identified initially by the design consultants for each of the respective design packages and recorded as part of their geotechnical design reports alongside the geotechnical design basis report, geotechnical design summary report and the geotechnical supervision and monitoring plan. These geotechnical design reports were specified in the project's civil engineering standards (Crossrail, 2009) and were compliant with Eurocode 7 (BSI, 2004). Resultant risk registers from each designer were incorporated into a project-wide geotechnical risk register to ensure consistent understanding of the risks and that appropriate management and mitigation was applied between interfacing contracts.
Information and case studies on the risk posed by tunnelling and excavation-induced ground settlement on existing structures and utilities can be found in the three volumes of Crossrail Project: Infrastructure Design and Construction published to date (Black, 2016; Black et al., 2015a, 2015b).

\section{Targeted ground investigations}

Crossrail ground investigations were undertaken over a number of years, reflecting earlier aborted phases of development of the hybrid bill, the mechanism through which parliamentary approval and the powers to build Crossrail were achieved.

Following recommendations concerning a new east-west rail service across the city made in the Central London Rail Study (DoT et al., 1989), engineering feasibility studies were started in preparation for the deposition of a private bill for Crossrail in November 1989. After a number of delays, the bill was finally deposited in autumn 1991 with a second reading scheduled for spring 1992, which was further deferred due to the government's ongoing commitment to London Underground's Jubilee line extension project, which was going through the legislative process at that time. The early scheme design work continued, however, culminating in the first large ground investigation undertaken for Crossrail during 1991. This was split into four packages and covered the central tunnelled section, which at that time was approximately $11 \mathrm{~km}$ of twin-running tunnels between Royal Oak and Allen Gardens, just east of Liverpool Street.

The second reading of the Crossrail bill eventually took place in the summer of 1993 but was rejected by the committee set up to hear it in the House of Commons in May 1994. In the 2 years leading up to this and for a short period afterwards, design work had continued and a total of 39 additional ground and structural investigations of various sizes were undertaken to address specific issues arising during the design.

Following this rejection of the bill, the project then went into a 6 year phase of route safeguarding while it awaited approval from the government to begin preparation of a new bill. This eventually came as a result of the Strategic Rail Authority's London EastWest Study (SRA, 2001), and Crossrail (in the incarnation of Cross London Rail Links Ltd) was formally re-launched in January 2002. A new ground investigation strategy was developed that took account of the existing 1990s geotechnical investigations as well as changes to the original alignment and the extension of the tunnelled section east of Liverpool Street. The new strategy also considered technical improvements and ensured that the technical specification for the geotechnical investigation was reflective of industry best practice. Additionally, a benchmarking exercise against other major tunnelling projects was undertaken to understand the likely scale and costs of further geotechnical investigations.

Between 2002 and 2011 a further 39 new packages of ground investigation were procured under a series of term contracts managed by Crossrail. These initially provided information for design development and assisted in the development of the hybrid bill documentation, not least the environmental statement. Later, they provided detailed ground information during the development of the tender design. The bill was finally passed in July 2008 when the Crossrail Act (Crossrail Act 2008) came into existence. 
A scoping philosophy was developed for the post-2002 investigations, which set general rules and principles for the design of future packages of work and which took full account of the ground investigations undertaken during the 1990s (Crossrail, 2006). In general the scoping philosophy defined the requirements for each element of the works.

\subsection{Running tunnels}

The requirements for the closed-face tunnel boring machine (TBM) drives of the running tunnels were as follows.

- Knowledge of the stratigraphy and its horizontal and vertical variation along the tunnelling corridor. The presence of faults, hard bands and zones of softened or brecciated material needed to be identified where possible, or the potential for their occurrence investigated and assessed.

- Knowledge of the groundwater level, porewater pressure profile and groundwater flow at the tunnel horizons and in close proximity to the tunnels, particularly where high-permeability water-bearing strata were present within low-permeability strata. This information is particularly important where the tunnels interface with cross-passages and other junctions where hand mining or sprayed concrete linings (SCL) are to be used.

- Description and classification of the soils, including grading, plasticity, strength and stiffness, as well as abrasivity, which are used in the design of the TBMs and the tunnel linings.

- Testing of the chemical composition of the ground and groundwater within and around the excavated tunnel profiles (minimum of two tunnel diameters around the tunnel in general) to assess the aggressiveness to buried concrete and tunnel linings, identify the presence of swelling clay that may impact on the selection and operation of the TBMs, assess the potential for deoxygenation or noxious ground gas and understand potential problems relating to spoil handling and disposal.

- Measurements of in situ stresses and permeabilities at intermediate shaft sites to inform the design of the shaft linings and tunnel junctions.

\subsection{Shafts, portals and box stations}

The geotechnical investigation requirements for shafts, portals and box stations were as follows.

- Knowledge of the stratigraphy and its variation with depth, from the ground surface to a depth well below the base of shafts and/ or the base of the excavations or where any retaining walls are designed to support the excavations. Lateral and longitudinal variations needed to be investigated, particularly for portals as these extend over significant distances. The presence of faults, hard bands and zones of softened or brecciated material needed to be identified where possible, or the potential for their occurrence investigated and assessed.

- Knowledge of the groundwater level, porewater pressure profiles and particularly the direction of groundwater flow in any aquifers encountered was required over the whole depth of the shaft and portal excavation and the ground below and surrounding the excavation. The presence of water-bearing layers and the pressures operating in those layers have a major influence on the stability of excavations and the selection of techniques for shaft sinking and excavation. Understanding the groundwater regime was also critical to assessing the potential impact of the temporary and permanent works on groundwater flows.

- Description and classification of the soils, including grading, plasticity, strength and stiffness, in situ stresses and permeability to be used in the design of the shafts and retaining walls, selection of shaft sinking and excavation techniques, the design of groundwater control measures (if required) and the design of linings for the shafts.

- Testing of the chemical composition of the ground and groundwater within and around the proposed excavations to assess the aggressiveness to buried concrete, shaft linings and retaining walls, identify any contaminants present, assess the potential for deoxygenation or noxious ground gas and understand potential problems relating to spoil handling and disposal.

\subsection{Tunnelled stations, cross-overs and junctions}

The geotechnical investigation requirements for the tunnelled stations, cross-overs and junctions were as follows.

- Knowledge of the stratigraphy and its horizontal and vertical variation across the entire footprint of the station. The presence of faults, hard bands and zones of softened or brecciated material needed to be identified where possible, or the potential for their occurrence investigated and assessed.

- Knowledge of the groundwater level, porewater pressure profiles and the direction of flow in the groundwater in any aquifers encountered was required over the whole depth of the station tunnels and in the zone around the tunnels. As noted previously, the presence of water-bearing layers and the pressures operating in them will have a major influence on the stability of excavations, the design of tunnel linings and the choice of excavation technique. Understanding the groundwater regime was also critical to assessing the potential impact of both temporary and permanent works on groundwater flows.

- Description and classification of the soils (grading, plasticity, strength and stiffness, in situ stresses and permeability) to be used in the design of the excavations and tunnel linings, the selection of excavation techniques and sequences, and the design of groundwater control measures (if required).

- Testing of the chemical composition of the ground and groundwater within and around the proposed tunnels to assess aggressiveness to buried concrete and tunnel linings, identify any contaminants present, assess the potential for deoxygenation or noxious ground gas and understand potential problems relating to spoil handling and disposal.

\subsection{Ground investigation techniques}

A wide spectrum of drilling, sampling and testing techniques was used to investigate the ground and groundwater conditions and provide information to address the specific aims of the scoping philosophy outlined above. These included the following

- boring and sampling using cable percussion and rotary boreholes, thin-walled and window sampling techniques 
- in situ testing - standard penetration tests, piezocone penetration tests, self-boring pressuremeter tests, Menard pressuremeter tests, packer permeability tests, high-pressure dilatometer tests and pumping tests

- geophysical investigation - predominantly undertaken overwater and comprising seismic ('boomer' and 'pinger') profiling, magnetometer surveys, down-hole geophysical logging and down-hole and cross-hole measurement of seismic wave velocities

- groundwater monitoring - standpipe and multi-level piezometers utilising down-hole data loggers ('divers') and 'push-in' piezometers

- standard laboratory testing - classification and index tests, unconsolidated undrained triaxial tests, oedometer consolidation and swelling tests and shear box tests

- advanced laboratory testing including microfabric studies such as petrographic analyses and x-ray diffraction; suction and shear-wave measurements; unconsolidated, isotropically consolidated and anisotropically consolidated triaxial tests; mid-height porewater pressure measurements; measurement of shear-wave velocities using bender elements

- geoenvironmental sampling and testing of soil, groundwater and gas.

Excluding any late investigations undertaken by the main works contractors to address specific construction issues, a total of 1906 exploratory holes were bored, totalling approximately $38 \mathrm{~km}$ of borings. Of these, 381 were rotary cored $(17 \mathrm{~km})$ and 1200 holes had groundwater monitoring equipment installed and these were regularly monitored during the works. A further 1084 third-party borehole logs were collated, reviewed for quality and incorporated into the geotechnical database. These totalled a further $39 \cdot 5 \mathrm{~km}$ in length.

\section{Interpretative reporting}

Due to the prolonged nature of the ground investigation phase, responsibility for analysis of the geotechnical investigation data and development of the interpretative report evolved over time. In the early 1990s, Crossrail engaged several engineering consultants to complete various elements of the feasibility design. One of these consultants, Arup, was appointed as the engineer for the initial phase of ground investigations and subsequently tasked with developing a route-wide geotechnical sectional interpretative report covering the route between Royal Oak portal and what was then the eastern portal at Allen Gardens, north-east of Liverpool Street station.

Post-2000, Crossrail appointed a specialist geotechnical advisor, Geotechnical Consulting Group, the remit of which included responsibility for assimilating all the new ground investigation information and updating the interpretative report as well as extending the scope of the report to include the new alignment out to Pudding Mill Lane and Plumstead in the east.

The benefits of having a client-led geotechnical interpretative report were significant given the long period over which the investigative works were undertaken. This allowed for a consistent approach in the reporting and enabled a better understanding of how the geological conditions and ground risk varied in the context of the project's regional setting. It also saved significant time when the multi-disciplinary designers for each phase of scheme development were appointed, allowing the client to run geotechnical briefing sessions that assisted in ensuring a consistent understanding of the ground across the project.

\section{Lessons learned}

All tunnelling work has now been completed and all major station boxes, shafts and portals are finished. In the majority of cases, geotechnical hazards have not been as severe as anticipated and where they have, the design and, management of mitigation to avoid the risk posed by these hazards has been successfully employed.

The following sections focus on some of the key hazards identified in the list presented in Section 3 and summarise the extent to which these manifested as risks that impacted on the Crossrail works, with some specific examples and references to further reading where appropriate.

\subsection{Groundwater}

Groundwater was probably the most significant hazard as it would potentially impact on much of the central tunnelled section. Apart from consideration during design of the long-term groundwater effects on the permanent works, risk resulting from groundwater was most significant in the temporary case and was therefore the contractor's responsibility to manage and mitigate where necessary.

Dewatering and depressurisation was employed on a number of contracts, although it was most extensively used on contract C305 for the eastern running tunnels, which covered the tunnel route between Farringdon station in the west and the portals at Pudding Mill Lane and Victoria Dock in the east. It also encompassed the junctions at Stepney Green, which split the route into its two eastern branches, several cross-passages, connections to four sub-surface stations and two large shafts (one permanent and one temporary) at Limmo Peninsula.

The Stepney Green works were of particular concern with regard to groundwater as the lower levels of both the eastbound and westbound junctions penetrated into the Lambeth Group deposits, where the ground investigation had shown there to be water-bearing sand units (see Figure 4). The junctions consisted of two very large SCL caverns, $17 \mathrm{~m}$ wide, $50 \mathrm{~m}$ long and $13 \mathrm{~m}$ from crown to invert. Due to their size and the nature of the ground, the excavation was divided into two sidewall drifts with a central pillar that was subsequently excavated to form the final profile.

An extensive array of surface dewatering wells was installed to reduce the water levels to below the level of the excavation, but it became apparent early on that the high permeability and recharge of the sand units meant that surface dewatering alone would be insufficient to achieve this. The solution proposed by the contractor and successfully employed during construction was to supplement the surface dewatering with in-tunnel depressurisation; this was installed as the tunnel advanced to locally control the levels in the area of active excavation. More detail can be found in the work of Harris et al. (2015). 


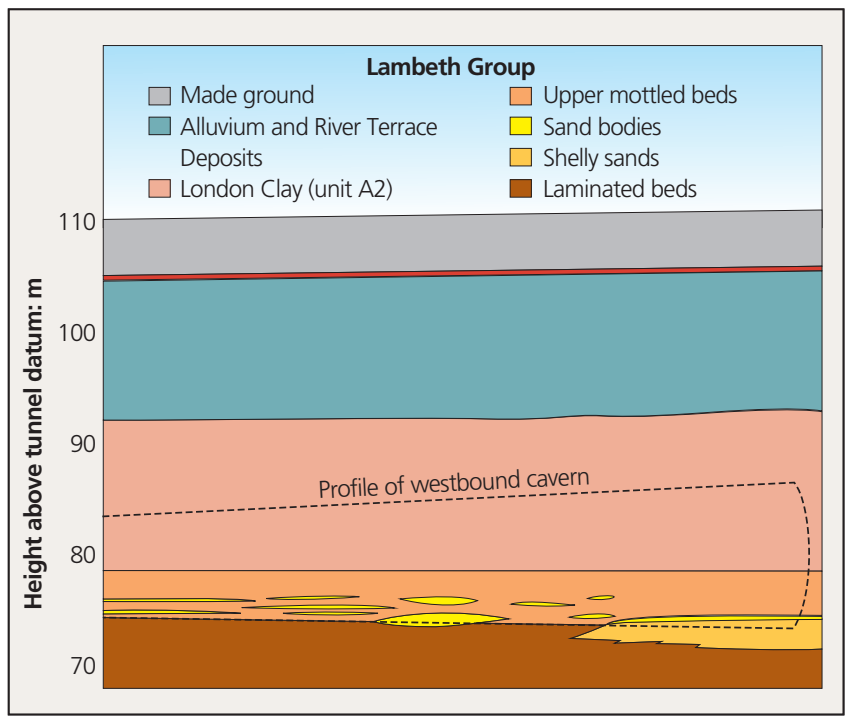

Figure 4. Geological profile of the westbound cavern at Stepney Green showing water-bearing sand units

Another issue arising from dewatering was the potential for air entrapment during recovery. In certain sections of the route where dewatering was undertaken, there was a risk of trapping air above the phreatic surface in geological structural traps when the groundwater levels recovered. This phenomenon became apparent during the Crossrail ground investigation works when drilling in the Docklands area hit a pocket of pressurised air on penetrating beneath the Lambeth Group clays. On later review, it became apparent that this air had become trapped during earlier phases of dewatering associated with the development of the area.

On testing, it was discovered that the air was depleted of oxygen, probably due to the oxidation of 'green rust' and other reactive minerals in the ground. The problems that this phenomenon presents are two-fold. Firstly, the pressurised air could exert unacceptable base heave on deep structures. Secondly, it could, in some situations, force deoxygenated air into the Crossrail tunnels either during construction or into the operational railway environment, particularly where ventilation is limited. This issue is further described by Newman et al. (2013).

Mitigation of this phenomenon was achieved by the phased switching-off of dewatering to ensure that air was able to naturally migrate away from the structural traps. Several ventilation wells were also installed to ensure that any remaining air was able to escape freely.

\subsection{Mixed face conditions}

The risk from variable ground was present to some extent wherever the tunnels and excavations encountered the Lambeth Group deposits. A good example is at Farringdon station, where the SCL tunnels were driven through the entire Lambeth Group sequence, complicated by a series of sub-parallel normal faults with throws of up to $9 \mathrm{~m}$ running transverse to the station's longaxis (see Figure 5).

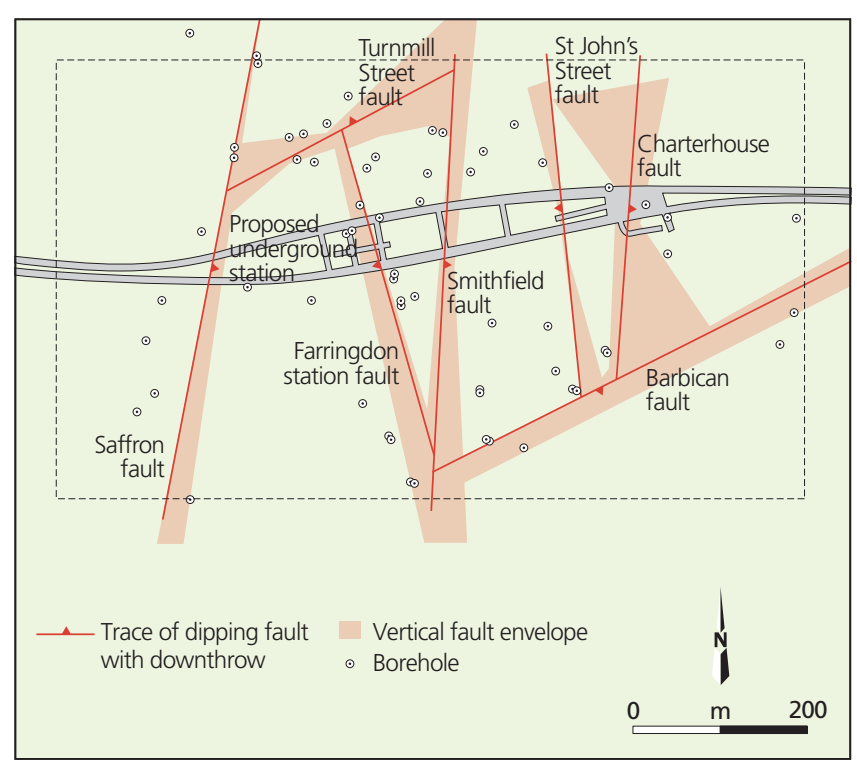

Figure 5. Detail of the faulting around Farringdon station

The potentially problematic ground conditions were highlighted early on in the ground investigations and further phases of geotechnical investigation were undertaken at this location to refine the detail further. The surface development in this area, with Smithfield Market and the London Underground and Thameslink lines in cutting, made surface access for boreholes particularly challenging and resulted in some areas of the Crossrail station footprint with less than optimal coverage.

To assist in understanding the stratigraphy and faulting better, Crossrail employed the services of the British Geological Survey (BGS) to produce a detailed three-dimensional ground model of the station from the available information. This modelling work is described in detail by Aldiss et al. (2012). This model was subsequently adopted by the contractor for Farringdon station, who then worked with the BGS to refine and update the model as construction of the station progressed.

This development of the model showed that the distribution of water-bearing sand units and sand channels was more extensive than anticipated from the geotechnical investigation information and the updated model is described in detail by Gakis et al. (2016). As the model was progressively refined, it became a very useful predictive tool for the contractor during construction, who was better able to understand the distribution and extent of these sand units and ensure that an appropriate toolbox of mitigation measures was on hand to deal with them (see Figure 6).

It was found that sand units in the upper mottled beds of the Lambeth Group were up to $3 \mathrm{~m}$ thick, water-bearing and recharged, with pore pressures up to $100 \mathrm{kPa}$. Those encountered in the lower mottled beds, however, tended to be dry, having been affected by underdrainage into the lower aquifer as a result of historic extraction. These sand units could potentially create unstable faces in the SCL construction, exacerbated by any groundwater present, so a programme of advanced probing was undertaken (assisted by the 
Civil Engineering

Volume 170 Issue CE5
Crossrail project: managing geotechnical

risk on London's Elizabeth line

Black

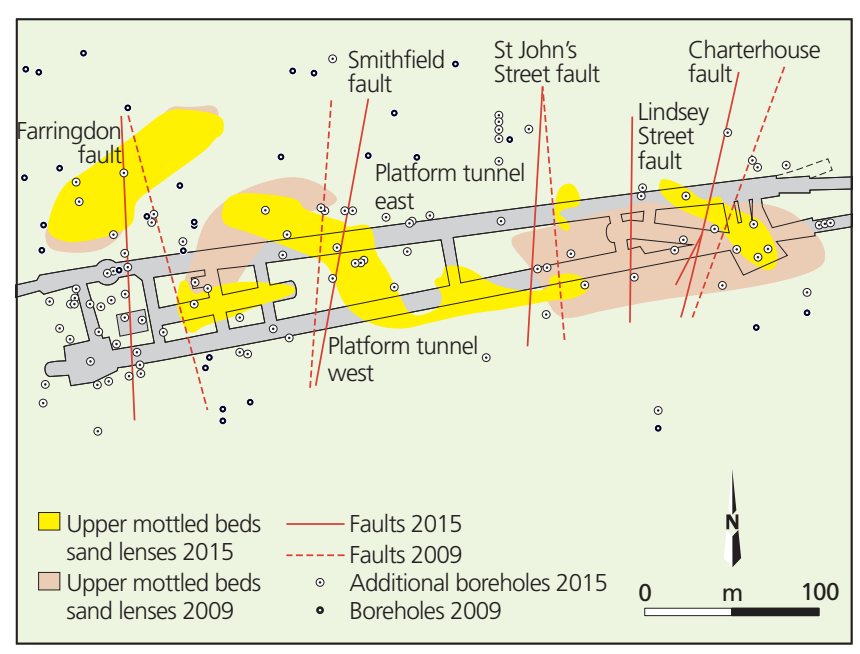

Figure 6. Distribution of Lambeth Group water-bearing sand units at Farringdon station

presence of the TBM-driven pilot tunnel that passed through the station in advance of enlarging to the full platform tunnel profile). Once the presence of sand had been proven, permeation grouting was employed in the larger sand bodies to reduce groundwater flow and, in some situations, local temporary support in the form of boards was applied to the exposed sand prior to spraying the primary SCL.

The faulting, while extensive and with a number of additional faults identified since the original BGS modelling, did not present any significant problems to construction. Overall, the faults tended to be relatively tight with minimal disturbed ground around them and no noticeable groundwater flows along the fault planes (see Figure 7).

\subsection{Obstructions}

Obstructions are a significant risk that are not easily identifiable through physical investigation. Crossrail undertook a very extensive desk study of possible obstructions to identify deep foundations (both for structures and temporary works), wells, hydraulic lift rams, boreholes and so on. Although a large number of potential obstructions were identified, the search was only as good as the information available and it was therefore anticipated that some uncharted obstructions would be encountered.

The TBMs on all three main running tunnel contracts encountered obstructions in the ground, while wells were encountered on three separate station sites during the SCL works. The TBM obstructions were identified as borehole casings (on two occasions), a groundwater abstraction hole and a series of raked temporary steel piles. The boreholes and abstraction hole did not cause any significant damage or delays to the TBMs and were only noticed when fragments of casings were discovered on the spoil conveyer after they had passed through the TBM's screw assembly. The raked steel piles on the other hand caused a significant delay to the works and had to be removed by constructing a temporary timber adit ahead of the TBM head and burning them out. These steel piles had been identified in the obstructions desk study but it was assumed their angle of installation would not situate them in the tunnel profile.

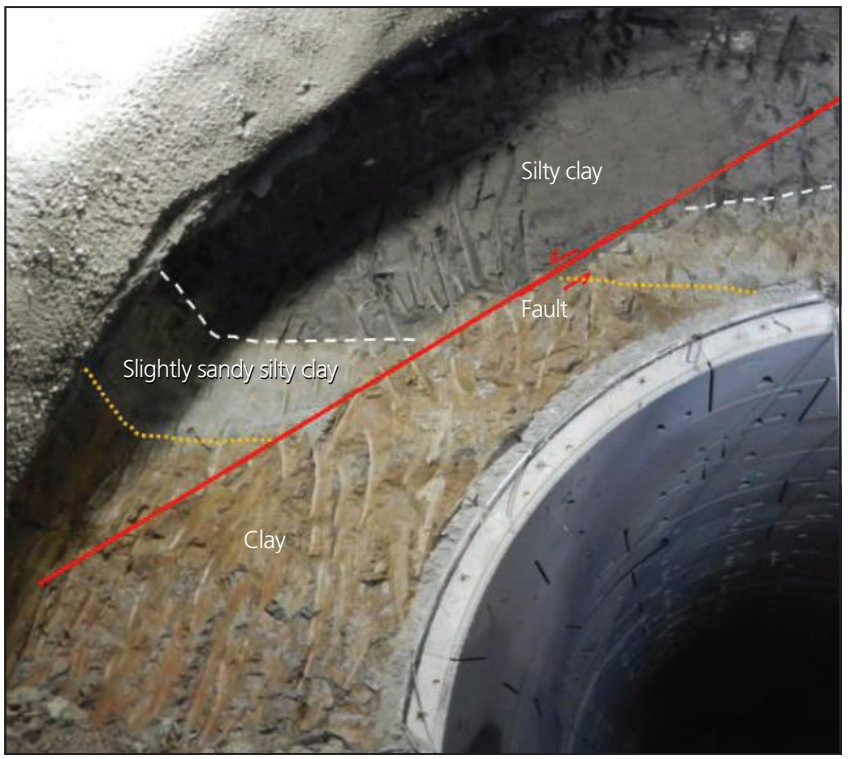

Figure 7. Faulted Lambeth Group strata at Farringdon station

The wells encountered in the SCL works comprised two bricklined structures at Bond Street and Tottenham Court Road and a steel-lined well at Liverpool Street (see Figure 8). While the presence of two of these wells was known or suspected, it was not anticipated that they would be found within the tunnel profile. This highlights the fact that, even with available information, a level of caution needs to be maintained with regard to its accuracy or reliability.

\section{Conclusions}

This paper provides some examples of how geotechnical risk manifested and was managed on Crossrail during the construction phase. Other examples are documented in the Crossrail learning legacy website (Crossrail, 2016) and in volumes 1 to 3 of Crossrail Project: Infrastructure Design and Construction (Black, 2016; Black et al., 2015a, 2015b).

It is important to note that of the relatively small number of geotechnical risk related issues that did arise during construction, the vast majority were minor in terms of their impact on the programme and this is testament to the well-structured and methodical process of risk identification, investigation and mitigation through design. A thorough understanding of the ground through detailed desk studies, targeted ground investigations and consistent client-led interpretative reporting as well as reviewing the lessons learned from other construction projects in London ensured that risks could be identified, clearly defined and appropriately dealt with.

It is also worth noting that major projects such as Crossrail present an excellent opportunity to collaborate with researchers in both academia and the industry to further knowledge and understanding and consequently continue to reduce the risk from the ground in future projects. 


\section{Civil Engineering}

Volume 170 Issue CE5
Crossrail project: managing geotechnical

risk on London's Elizabeth line

Black

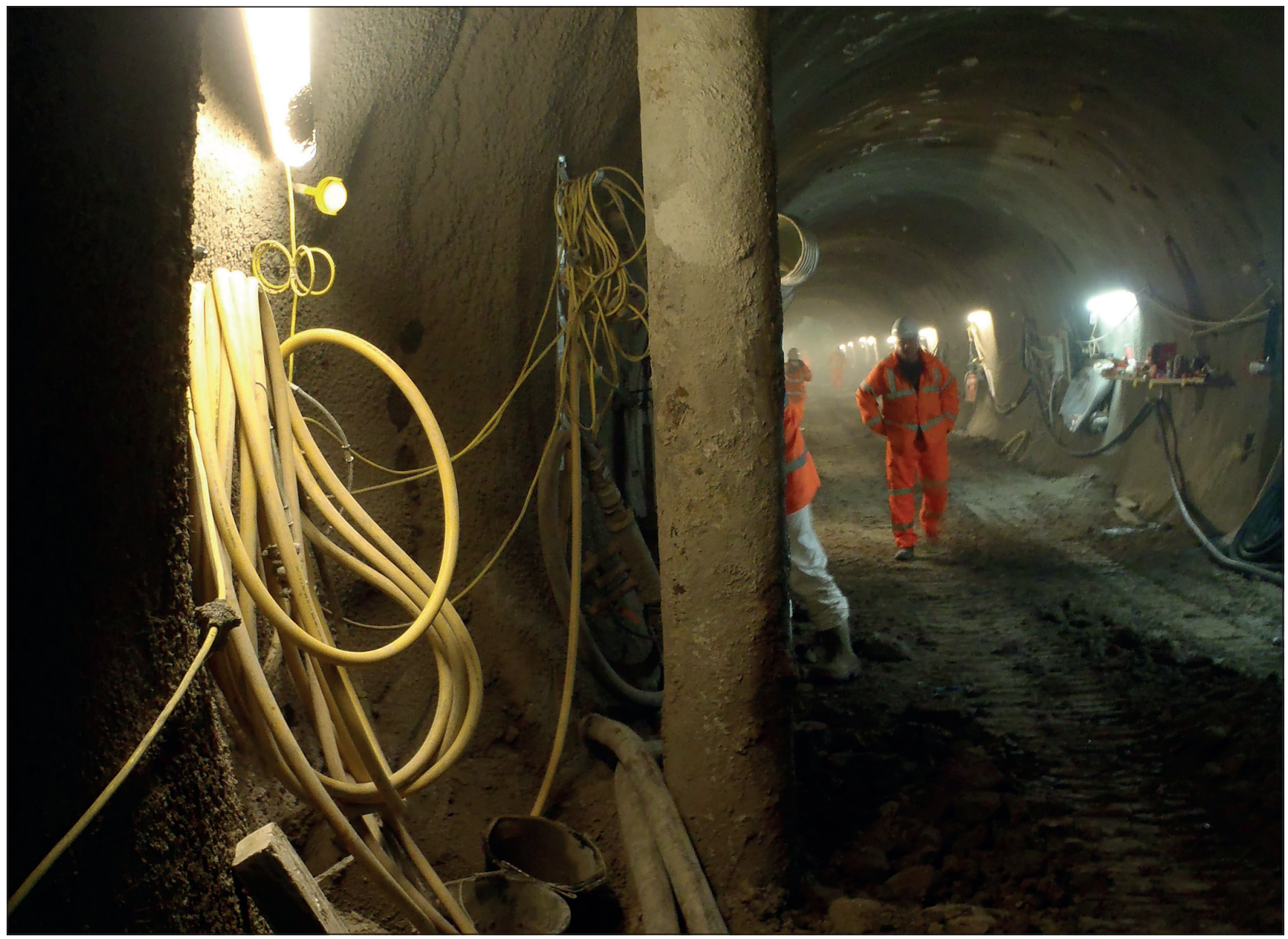

Figure 8. Steel-lined well in the grouting adit at Liverpool Street station

\section{References}

Aldiss DT (2013) Under-representation of faults on geological maps of the London region: reasons, consequences and solutions. Proceedings of the Geologists' Association 124(6): 929-945.

Aldiss DT, Black MG, Entwisle DC, Page DP and Terrington RL (2012) Benefits of a 3D geological model for major tunnelling works: an example from Farringdon, east-central London, UK. Quarterly Journal of Engineering Geology and Hydrogeology 45(4): 405-414.

Black M (ed.) (2016) Crossrail Project: Infrastructure Design and Construction, Vol. 3. ICE Publishing, London, UK

Black M, Dodge C and Lawrence U (eds) (2015a) Crossrail Project: Infrastructure Design and Construction, Vol. 1. ICE Publishing, London, UK.

Black M, Dodge C and Yu J (eds) (2015b) Crossrail Project: Infrastructure Design and Construction, Vol. 2. ICE Publishing, London, UK.

BSI (2004) BS EN 1997-1: 2004. Eurocode 7: Geotechnical Design. BSI, London, UK.

Crossrail (2006) Re-scoping of Ground Investigations for Crossrail Line 12006 Rev A. Crossrail, London, UK.

Crossrail (2009) Civil Engineering Design Standard: Part 20 Geotechnical Design and Baseline Report Deliverables. Crossrail, London, UK.
Crossrail (2016) http://uww.learninglegacy.crossrail.co.uk (accessed 20/12/2016). Crossrail Act 2008. Chapter 18. Her Majesty's Stationary Office, London, UK.

Davis I (2016) A geology of London for tunnellers and engineers. In Crossrail Project: Infrastructure Design and Construction, Vol. 3 (Black M (ed.)). ICE Publishing, London, UK, pp. 447-458.

DoT, BRNS, LRT and LU (Department of Transport, British Rail Network Southeast, London Regional Transport and London Underground Ltd) (1989) Central London Rail Study. Department of Transport, London, UK.

Gakis A, Cabrero P, Entwisle D and Kessler H (2016) 3D geological model of the completed Farringdon underground railway station. In Crossrail Project: Infrastructure Design and Construction, Vol. 3 (Black M (ed.)). ICE Publishing, London, UK, pp. 431-446.

Harris D, Davis A and Linde E (2015) Crossrail sprayed concrete lining depressurisation at Stepney Green Caverns. In Crossrail Project: Infrastructure Design and Construction, Vol. 1 (Black M, Dodge C and Lawrence U (eds)). ICE Publishing, London, UK, pp. 597-616.

Newman TG, Ghail RC and Skipper JA (2013) Deoxygenated gas occurrences in the Lambeth Group of central London. Quarterly Journal of Engineering Geology and Hydrogeology 46(2): 167-177.

Royse KR, de Freitas M, Burgess WG et al. (2012) Geology of London, UK. Proceedings of the Geologists' Association 123(1): 22-45.

SRA (Strategic Rail Authority) (2001) London East-West Study. SRA, London, UK. 